\title{
Optimisasi Portofolio Expected Shortfall pada Saham Sektor Energi dan Pertambangan
}

\author{
Nurul Fadilah", a), Betty Subartini, ${ }^{1, b)}$, Firman Sukono ${ }^{1, c)}$ \\ ${ }^{1}$ Departemen Matematika, Fakultas Matematika dan IImu Pengetahuan Alam, Universitas Padjadjaran \\ a) email: fadil.nurulf@gmail.com \\ b) email: betty.subartini@unpad.ac.id \\ c)email: sukono@unpad.ac.id
}

\begin{abstract}
Abstrak
Saham sebagai salah satu produk investasi di pasar modal Indonesia tentunya memiliki risiko yang dapat memengaruhi keputusan investor dalam berinvestasi. Dalam menentukan risiko dapat dilakukan dengan melihat diversifikasi portofolio dari beberapa saham. Data saham meliputi perusahaan energi dan pertambangan yang memenuhi kriteria kapitalisasi pasar besar dan Debt to Equity Ratio (DER) rendah. Salah satu metode yang dapat digunakan untuk membentuk diversifikasi portofolio adalah Expected Shortfall (ES). ES adalah nilai ekspektasi dari return, jika return tersebut melampaui batas maksimum (Value-at-Risk) dengan tujuan untuk memperkecil risiko investasi. Dari perhitungan ES didapat masingmasing proporsi saham dalam satu portofolio optimal, dari beberapa portofolio yang dibentuk terlihat bahwa portofolio yang terdiri dari kombinasi saham paling banyak maka portofolio tersebut menghasilkan risiko yang paling rendah. Data dalam penelitian ini adalah data harga penutupan saham harian sektor energi dan pertambangan periode Januari 2016 - Januari 2019. Ada beberapa tahap dalam penelitian ini. Langkah pertama adalah menghitung nilai return setiap saham perusahaan. Kemudian menghitung nilai expected return dan korelasi antar saham dari setiap saham perusahaan. Setelah itu pembentukan portofolio dan perumusan portofolio dengan menggunakan Expected Shortfall dengan fungsi tujuan yang dibentuk. Dari portofolio yang dibentuk, dipilih kombinasi saham yang paling kecil risikonya.
\end{abstract}

Kata kunci: saham, risiko, optimisasi, expected shortfall

\begin{abstract}
Stocks as one of the investment products in the Indonesian capital market, certainly have risks that can affect investor decisions in investing. Determining risk can be done by looking at the diversification of the portfolio of several stocks. Stock data includes energy and mining companies that fulfill the criteria for large market capitalization and low Debt to Equity Ratio (DER). One method that can be used to form portfolio diversification is the Expected Shortfall (ES). ES is is the Expected value of the return if the return exceeds the maximum return limit (Value-at-Risk), with the aim of minimizing investment risk. From the ES calculation, each proportion of stocks in an optimal portfolio is obtained, from several portfolios formed, it can be seen that the portfolio which consists of the most combination of shares, the portfolio produces
\end{abstract}


the lowest risk. The data in this study are data on closing prices of the daily shares of the energy and mining sectors for the period January 2016 - January 2019. There are several stages in this study. The first step is to calculate the return value of each company stock. Then calculate the expected return value and the correlation between shares of each company stock. After that, portfolio formation and portfolio formulation using Expected Shortfall with the objective function formed. From the formed portfolio, the combination of stocks with the least risk will be selected.

Keywords: stocks, risk, optimization, expected shortfall

\section{Pendahuluan}

Investasi adalah salah satu variabel terpenting dalam ekonomi. Dengan investasi berarti produksi barang yang akan digunakan untuk menghasilkan barang lain. Definisi ini berbeda dari penggunaan populer, di mana keputusan untuk membeli saham atau obligasi dianggap sebagai investasi. Investasi biasanya merupakan hasil dari konsumsi yang berkelanjutan [1].

Investasi banyak macamnya, salah satunya saham. Saham atau juga dikenal sebagai ekuitas adalah jenis keamanan yang menandakan kepemilikan proporsional dalam perusahaan penerbit. Ini memberikan hak kepada pemegang saham atas proporsi aset dan pendapatan korporasi. Investor akan membeli saham ketika harga saham undervalue dan menjual saham saat harga saham dinilai sangat tinggi. Membeli saham saat harga rendah dan menjual saham saat harga naik menyebabkan investor mendapat untung. Dalam berinvestasi apalagi saham, tentunya memiliki risiko yang mengakibatkan kerugian terhadap investor.

Risiko tidak dapat dihilangkan, namun dapat diminimalkan. Pengukuran risiko dan pengoptimalan memerlukan metrik, ukuran risiko. Dalam teori asli Optimalisasi portofolio Markowitz [2]. Perlakuan simetris dari kerugian dan keuntungan dianggap tidak dapat dibenarkan dari sudut pandang investor, oleh karena itu ide pengukuran risiko downside, yang hanya berfokus pada kerugian diubah dengan memaksimalkan keuntungan [3]. Usaha untuk meminimalkan risiko dalam berinvestasi banyak dilakukan oleh investor. Salah satu metode yang digunakan dalam usaha meminimalkan risiko investasi adalah metode Expected Shortfall (ES), secara umum ES didefinisikan sebagai ekspektasi ukuran risiko yang nilainya di atas Value-at-Risk (VaR). Sedangkan VaR merupakan kerugian (return negatif) maksimum yang mungkin terjadi selama periode waktu pada tingkat kepercayaan tertentu [4].

Beberapa peneliti menggunakan Expected Shortfall (ES) sebagai alternatif ukuran risiko dari Valueat-Risk (VaR). Pada tahun 2000, Rockafellar dan Uryasev memperkenalkan untuk pertama kalinya ES dan rumus untuk meminimalkannya dalam optimalisasi. Sebagai ukuran risiko alternatif, ES dikenal lebih aman dibandingkan dengan VaR. Karena VaR mengabaikan setiap kerugian yang melampaui tingkat VaR [5]. Setelah itu cukup banyak penelitian tentang metode Expected Shortfall, seperti pada penelitian Tasche et.al. [6], menjelaskan tentang risiko Expected Shortfall sebagai alternatif untuk menghitung Value-at-Risk karena merupakan risiko yang koheren, meskipun dalam kenyataannya masih banyak cara yang dapat dilakukan untuk menyelidiki lebih baik dalam masalah statistik, probabilistik dan komputasi yang diangkat oleh penggunaan ES, namun ES dapat lebih teliti lagi dalam penggunaannya, dan semua teknik yang dikembangkan dalam beberapa tahun terakhir bertujuan untuk efisiensi perhitungan VaR. Kemudian pada penelitian yang dilakukan oleh Kondor et.al. [7] mengatakan semakin besar panjang deret waktu yang diperlukan untuk optimalisasi portofolio akan membuat semakin rendah nilai risikonya sehingga memperkecil kemungkinan kerugian yang lebih besar dalam investasi. Lalu dijelaskan lebih dalam pada penelitian yang dilakukan Caccioli et.al. [8] menjelaskan bahwa ES mempertimbangkan masalah pemilihan 
portofolio optimal di bawah ukuran risiko, walaupun ES mempertimbangkan hal yang diabaikan oleh VaR, tetapi nilai ES juga masih sangat tinggi, sehingga perlu pengembangan atau metode lain untuk memperkecil nilai kerugiannya. Tetapi ES jauh lebih baik daripada VaR, karena VaR dari portofolio yang dioptimalkan ES.

Berdasarkan uraian di atas, pada penelitian ini akan dikaji model Expected Shortfall (ES) untuk menentukan pemilihan portofolio saham optimal dari kombinasi saham beberapa perusahaan untuk memilih portofolio yang paling kecil risikonya. Model ES dipilih karena ES mempertimbangkan masalah pemilihan portofolio optimal di bawah ukuran risiko $(\mathrm{VaR})$, selain itu ES juga merupakan ukuran risiko yang koheren, sehingga dipilih untuk digunakan sebagai alat menghitung risiko portofolio.

\section{Metode}

\section{Objek Penelitian}

Objek dalam penelitian ini menggunakan data sekunder berupa data yang bersifat runtun waktu (time series) harian. Data yang dipilih adalah lima data penutupan saham (closing price) perusahaan yang terdaftar pada IDX yaitu Adaro Energy Tbk (ADRO), Aneka Tambang Tbk (ANTM), Bumi Resource Tbk (BUMI), Surya Esa Perkasa Tbk (ESSA), Vale Indonesia Tbk (INCO). Perusahaan dipilih dengan kriteria tingkat kapitalisasi pasar tinggi dan DER yang rendah. Jangka waktu saham yang digunakan sejak bulan Januari 2016 - Januari 2019. Diasumsikan dana investasi terbatas sebesar 1 milyar rupiah. Metode yang digunakan dalam penelitian ini adalah Expected Shortfall (ES), dibentuk menggunakan metode pengali Lagrange (Lagrange Multipiers).

\section{Tingkat Return Asset}

Model penetapan harga aset berupaya untuk menghubungkan pengembalian yang diharapkan saham dengan atributnya. Model penetapan harga aset klasik, seperti Sharpe et.al. [9], Lintner et.al. [10] dan Black et.al. [11], memprediksi bahwa pengembalian aset yang diharapkan harus secara positif terkait dengan risiko pasar sistematisnya. Return merupakan salah satu faktor yang memotivasi investor berinteraksi dan juga merupakan imbalan atas keberanian investor dalam menanggung risiko atas investasi yang dilakukannya. Singkatnya return adalah keuntungan yang diperoleh investor dari dana yang ditanamkan pada suatu investasi [12]. Rumus total tingkat pengembalian suatu investasi saham dapat ditulis sebagai berikut:

$$
\text { Return total }=\text { yield }+ \text { Capital gain atau Capital loss }
$$

Cara memperoleh return sendiri dapat dihitung menggunakan rumus:

$$
R_{i, t}=\frac{P_{i, t}-P_{i, t-1}}{P_{i, t-1}}
$$

dengan ekspektasi return saham:

$$
E(R)=\frac{\sum_{i=1}^{n} R_{i, t}}{n}
$$

Keterangan: $R_{i, t}$ : Return saham i pada waktu $t ; P_{i, t}$ : Harga saham i pada periode $t$; dan $P_{i, t-1}$ : Harga saham i pada periode $t-1$.

\section{Tingkat Return Portofolio}

Portofolio adalah kumpulan dari instrument investasi yang dibentuk untuk memenuhi suatu sasaran umum investasi, jika seorang investor berkeinginan untuk memaksimumkan keuntungan yang diharapkan daripada portofolio, dana sebaiknya diletakkan dalam sekuritas yang mempunyai harapan keuntungan 
yang maksimum [2]. Dalam proses perhitungan return portofolio, beberapa hal yang perlu diperhatikan adalah proporsi dari masing-masing saham dan return dari saham tersebut. Jumlah proporsi dari saham $\left(w_{i}, i=1 \ldots n\right)$ pada suatu portofolio sama dengan satu, atau jika ditulis secara matematis:

$$
\sum_{i=1}^{n} w_{i}=1
$$

Perhitungan return portofolio dilakukan dengan rumus:

$$
R_{p}=w_{1} R_{1}+w_{2} R_{2}+\cdots+w_{n} R_{n}=\sum_{i=1}^{n} w_{i} R_{i}
$$

Selain perhitungan return, perhitungan ekspektasi return juga diperlukan sebagai penanda rata-rata tertimbang dari tingkat keuntungan yang diharapkan dari masing-masing aset pada portofolio. Perhitungan expected return dilakukan menggunakan rumus:

$$
\overline{R_{p}}=E\left[R_{p}\right]=w_{1} \overline{R_{1}}+w_{2} \overline{R_{2}}+\cdots+w_{n} \overline{R_{n}}=\sum_{i=1}^{n} w_{i} \overline{R_{l}}
$$

Keterangan: $w_{i}$ : proporsi aset $\mathrm{i} ; R_{p}$ : return portofolio; $\overline{R_{p}}$ : expected return portofolio; $\bar{R}_{l}$ : rata-rata asset $\mathrm{i}$

\section{Varian dan Kovarian Portofolio}

Secara matematis, rumus yang digunakan untuk menghitung varian dan kovarian adalah:

Varian

$$
\sigma^{2}=\frac{\sum_{i=1}^{n}\left[R_{i}-E(R)\right]^{2}}{n-1}
$$

Kovarian

$$
\sigma_{A B}=\frac{\sum_{i=1}^{n}\left[\left(R_{A, i}-E\left(R_{A}\right)\right) \cdot\left(R_{\mathrm{B}, i}-E\left(R_{B}\right)\right)\right]}{n-1}
$$

Keterangan: $R_{i}$ : return saham i; $E(R)$ : expected return saham

Untuk portofolio dari gabungan beberapa saham, misalkan terdapat dua saham yaitu saham $i$ dan saham $j$. Secara matematis, rumus yang digunakan untuk menghitung varians adalah:

$$
\sigma_{p}^{2}=\sum_{i j} w_{i} w_{j} \sigma_{i j}=\sum_{i=1}^{n} \sum_{j=1}^{n} w_{i} w_{j} \sigma_{i j}
$$

Keterangan: $\sigma_{p}^{2}$ : varian return portofolio; $\sigma_{i j}$ : kovarian antara return saham i dan j; $\sigma_{i i}$ : varian return saham $\mathrm{i} ; w_{i}$ : proporsi yang diinvestasikan pada saham $\mathrm{i} ; w_{j}$ : proporsi yang diinvestasikan pada saham j.

Varian dan kovarian portofolio dapat dibentuk sebagai matriks varian dan kovarian, sebagai berikut:

$$
\mathbf{V}=\left(\begin{array}{cccc}
w_{1}^{2} \sigma_{1}^{2} & w_{1} w_{2} \sigma_{12} & \cdots & w_{1} w_{n} \sigma_{1 n} \\
w_{2} w_{1} \sigma_{21} & w_{2}^{2} \sigma_{2}^{2} & \cdots & w_{2} w_{n} \sigma_{2 n} \\
\vdots & \vdots & \ddots & \vdots \\
w_{n} w_{1} \sigma_{n 1} & w_{n} w_{2} \sigma_{n 2} & \cdots & w_{n}^{2} \sigma_{n}^{2}
\end{array}\right)
$$

\section{Metode Expected Shortfall}

Expected Shortfall adalah nilai ekspektasi dari return jika return tersebut melampaui batas return maksimum (Value-at-Risk) [8]. Secara umum Expected Shortfall dapat ditulis secara matematis:

$$
\sigma_{w}^{2}=\frac{1}{N} \sum_{i}\left(w_{i}^{2}-\left(\overline{w_{l}}\right)^{2}\right)
$$

Karena nilai rata-rata $w_{i}$ selalu 1 , maka persamaan menjadi:

$$
\begin{aligned}
\sigma_{w}^{2}=\frac{1}{N} \sum_{i}\left(w_{i}^{2}-\left(\overline{w_{l}}\right)^{2}\right) & =\frac{1}{N} \sum_{i}\left(w_{i}^{2}-(1)^{2}\right) \\
& =\frac{1}{N} \sum_{i} w_{i}^{2}-1
\end{aligned}
$$


[Nurul Fadilah, dkk]

Bergantung pada jenis investor institusi, posisi mungkin terbatas atau bahkan dikecualikan oleh kendala hukum dan atau likuiditas [13]. Namun, ketika mereka hadir, bahkan jika tunduk pada batas, mereka berkontribusi besar terhadap ketidakstabilan ES oleh Acerbi dan Tasche [14],[15].

6. Model Optimisasi Portofolio

Pembentukan portofolio optimal dapat ditentukan menggunakan Expected Shortfall (ES), dengan fungsi tujuan yaitu meminimumkan varians.

Meminimalkan

$$
\sigma_{p}^{2}=\sum_{i j} w_{i} w_{j} \sigma_{i j}=\sum_{i=1}^{n} \sum_{j=1}^{n} w_{i} w_{j} \sigma_{i j}
$$

dengan syarat:

$$
\begin{aligned}
& \frac{1}{N} \sum_{i} w_{i}^{2}-1 \leq 0 \\
& \sum_{i=1}^{n} w_{i}=1
\end{aligned}
$$

Karena permasalahan optimisasi harus non-negative, maka syarat batasnya diubah menjadi:

Meminimalkan

$$
\sigma_{p}^{2}=\sum_{i j} w_{i} w_{j} \sigma_{i j}=\sum_{i=1}^{n} \sum_{j=1}^{n} w_{i} w_{j} \sigma_{i j}
$$

dengan syarat:

$$
\begin{aligned}
& 1-\frac{1}{N} \sum_{i} w_{i}^{2} \geq 0 \\
& \sum_{i=1}^{n} w_{i}=1
\end{aligned}
$$

\section{Hasil dan Diskusi}

Data yang digunakan dalam penelitian ini adalah data harga penutupan saham harian periode Januari 2016 - Januari 2019, secara ringkas disajikan pada Gambar 1.
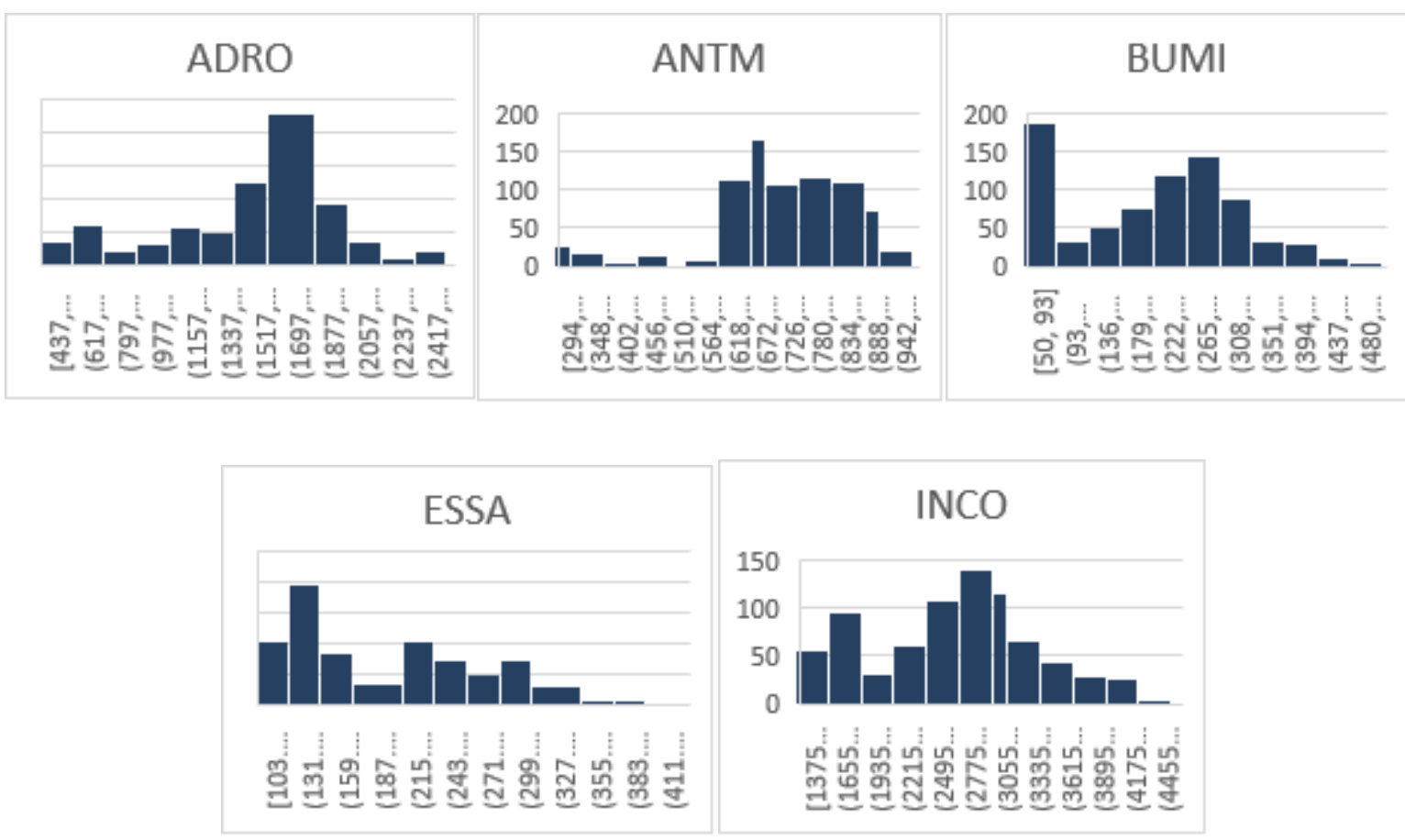

Gambar 1. Histogram Harga Penutupan Saham Harian

Gambar 1 menunjukkan bahwa histogram penutupan saham harian setiap perusahaan terpilih cenderung fruktuatif sehingga sebaran data dalam distribusi frekuensi tidak merata. 


\section{Perhitungan Return dan Ekspektasi Return}

Menghitung nilai return saham harian perusahaan terpilih yaitu Adaro Energy Tbk (ADRO), Aneka Tambang Tbk (ANTM), Bumi Resource Tbk (BUMI), Surya Esa Perkasa Tbk (ESSA), Vale Indonesia Tbk (INCO) dengan menggunakan persamaan (2).

Selanjutnya, menghitung ekspektasi return saham dan risiko setiap perusahaan dengan menggunakan persamaan (3) dan (7), disajikan pada Tabel 1:

Tabel 1. Ekspektasi Return Saham dan Risiko Periode Januari 2016 - Januari 2019

\begin{tabular}{llll}
\hline No. & Kode Saham & Ekspektasi Return & Risiko \\
\hline 1. & ADRO & 0.001333 & 0.000834 \\
2. & ANTM & 0.001523 & 0.000674 \\
3. & BUMI & 0.001562 & 0.002219 \\
4. & ESSA & 0.001252 & 0.001343 \\
5. & INCO & 0.001189 & 0.000882 \\
\hline
\end{tabular}

\section{Perhitungan Varian dan Kovarian Portofolio}

Perhitungan varian dan kovarian portofolio bertujuan untuk menentukan korelasi antar saham dengan menggunakan persamaan (8), matriks varian dan kovarian return saham ditunjukkan pada Tabel 2:

Tabel 2. Varian dan Kovarian Return Periode Januari 2016 - Januari 2019

\begin{tabular}{llrlll}
\hline $\begin{array}{c}\text { Kode } \\
\text { Saham }\end{array}$ & \multicolumn{1}{c}{ ADRO } & ANTM & \multicolumn{1}{c}{ BUMI } & \multicolumn{1}{c}{ ESSA } & \multicolumn{1}{c}{ INCO } \\
\hline ADRO & 0.000834 & 0.000185 & 0.000317 & 0.0000539 & 0.0000018 \\
ANTM & 0.000185 & 0.000674 & 0.000144 & 0.000156 & 0.000347 \\
BUMI & 0.000317 & 0.000144 & 0.002219 & 0.0000526 & 0.000203 \\
ESSA & 0.0000539 & 0.000156 & 0.0000526 & 0.001343 & 0.000119 \\
INCO & 0.0000018 & 0.000347 & 0.000203 & 0.000119 & 0.000882 \\
\hline
\end{tabular}

\section{Perhitungan Portofolio}

Perhitungan portofolio dihasilkan dari fungsi tujuan dan syarat masing-masing portofolio yang dibentuk dari persamaan pada sub bagian 2.2.5, dengan bantuan menggunakan Software Microsoft Excel memberikan hasil portofolio optimal atau memberikan nilai risiko minimum dari masing-masing portofolio dan rangkuman perhitungan Expected return yang disajikan pada Tabel 3 berikut ini.

Tabel 3. Perhitungan Risiko dan Return Portofolio

\begin{tabular}{cccccccc}
\hline \multirow{2}{*}{ Portofolio } & \multicolumn{5}{c}{ Proporsi } & \multirow{2}{*}{ Risiko } & \multirow{2}{*}{ Return } \\
\cline { 2 - 5 } & ADRO & ANTM & BUMI & ESSA & INCO & & \\
\hline$P_{1}$ & 0.4395 & 0.5605 & 0 & 0 & 0 & 0.000418 & $0.1438 \%$ \\
$P_{2}$ & 0.7531 & 0 & 0.2469 & 0 & 0 & 0.000667 & $0.1387 \%$
\end{tabular}

e-ISSN: 2686-0341 p-ISSN: 2338-0896 


\begin{tabular}{|c|c|c|c|c|c|c|c|}
\hline \multirow{2}{*}{ Portofolio } & \multicolumn{5}{|c|}{ Proporsi } & \multirow{2}{*}{ Risiko } & \multirow{2}{*}{ Return } \\
\hline & ADRO & ANTM & BUMI & ESSA & INCO & & \\
\hline$P_{3}$ & 0.6199 & 0 & 0 & 0.3801 & 0 & 0.000527 & $0.13 \%$ \\
\hline$P_{4}$ & 0.5140 & 0 & 0 & 0 & 0.4860 & 0.000429 & $0.1261 \%$ \\
\hline$P_{5}$ & 0 & 0.7810 & 0.2190 & 0 & 0 & 0.000542 & $0.1532 \%$ \\
\hline$P_{6}$ & 0 & 0.6797 & 0 & 0.3203 & 0 & 0.000483 & $0.1436 \%$ \\
\hline$P_{7}$ & 0 & 0.5860 & 0 & 0 & 0.4140 & 0.000467 & $0.1298 \%$ \\
\hline$P_{8}$ & 0 & 0 & 0.3754 & 0.6246 & 0 & 0.000849 & $0.1281 \%$ \\
\hline$P_{9}$ & 0 & 0 & 0.2693 & 0 & 0.7307 & 0.000672 & $0.1273 \%$ \\
\hline$P_{10}$ & 0 & 0 & 0 & 0.3906 & 0.6094 & 0.000561 & $0.1282 \%$ \\
\hline$P_{11}$ & 0.3750 & 0.4972 & 0.1279 & 0 & 0 & 0.000379 & $0.1456 \%$ \\
\hline$P_{12}$ & 0.3513 & 0.4286 & 0 & 0.2201 & 0 & 0.000339 & $0.1464 \%$ \\
\hline$P_{13}$ & 0.3480 & 0.3557 & 0 & 0 & 0.2963 & 0.000323 & $0.1357 \%$ \\
\hline$P_{14}$ & 0.5065 & 0 & 0.1662 & 0.3273 & 0 & 0.000458 & $0.1343 \%$ \\
\hline$P_{15}$ & 0.4455 & 0 & 0.1251 & 0 & 0.4294 & 0.000392 & $0.1298 \%$ \\
\hline$P_{16}$ & 0.4006 & 0 & 0 & 0.2292 & 0.3703 & 0.000341 & $0.1331 \%$ \\
\hline$P_{17}$ & 0 & 0.5638 & 0.1646 & 0.2716 & 0 & 0.000413 & $0.1456 \%$ \\
\hline$P_{18}$ & 0 & 0.5006 & 0.1521 & 0 & 0.3473 & 0.000409 & $0.1413 \%$ \\
\hline$P_{19}$ & 0 & 0.4432 & 0 & 0.2376 & 0.3192 & 0.000373 & $0.1426 \%$ \\
\hline$P_{20}$ & 0 & 0 & 0.1856 & 0.3247 & 0.4897 & 0.00047 & $0.1379 \%$ \\
\hline$P_{21}$ & 0.3058 & 0.3877 & 0.1042 & 0.2023 & 0 & 0.000313 & $0.1413 \%$ \\
\hline$P_{22}$ & 0.3101 & 0.3293 & 0.0918 & 0 & 0.2688 & 0.000304 & $0.1377 \%$ \\
\hline$P_{23}$ & 0.3542 & 0 & 0.0999 & 0.2124 & 0.3335 & 0.000317 & $0.129 \%$ \\
\hline$P_{24}$ & 0.2944 & 0.2873 & 0 & 0.1728 & 0.2455 & 0.000277 & $0.1391 \%$ \\
\hline$P_{25}$ & 0 & 0.3889 & 0.1234 & 0.2125 & 0.2752 & 0.000335 & $0.1378 \%$ \\
\hline$P_{26}$ & 0.2649 & 0.2684 & 0.0786 & 0.1633 & 0.2248 & 0.000263 & $0.1356 \%$ \\
\hline
\end{tabular}

Keterangan:

: Anggota portofolio

: Bukan anggota portofolio

Dari Tabel 3, portfolio yang berisikan kombinasi dari 2 saham adalah $P_{1}, P_{2}, P_{3}, \ldots, P_{10}$. Dari kombinasi portofolio yang sudah dibentuk, $P_{1}$ merupakan portofolio yang memiliki risiko terkecil dibandingkan portofolio kombinasi dua saham yang lain yaitu sebesar 0.000418 dengan tingkat return $0.1438 \%$. Untuk portofolio kombinasi dari tiga saham adalah $P_{11}, P_{12}, P_{13}, \ldots, P_{20}$. Dari kombinasi 
portofolio yang berisikan 3 saham, $P_{13}$ merupakan portofolio yang memiliki risiko terkecil yaitu 0.000323 dengan tingkat return $0.1357 \%$. Untuk kombinasi portofolio yang terdiri dari empat saham antara lain $P_{21}, P_{22}, P_{23}, P_{24}, P_{25}$, portofolio yang memiliki risiko terkecil dari kombinasi empat saham yaitu $P_{24}$ dengan risiko sebesar 0.000277 dan tingkat return sebesar $0.1391 \%$. Sedangkan untuk portofolio yang terdiri dari lima kombinasi saham yaitu $P_{26}$ memiliki risiko sebesar 0.000263 dan tingkat return sebesar $0.1356 \%$.

Dari Tabel 3 didapat portofolio yang memberikan risiko paling minimum adalah $P_{26}$ dengan risiko sebesar 0.000263 sedangkan Ekspektasi return harian sebesar $0.1356 \% . P_{26}$ yang terdiri dari lima saham (ADRO, ANTM, BUMI, ESSA dan INCO), dengan proporsi saham ADRO, BUMI, ANTM, ESSA, INCO secara berurutan sebesar $26.49 \%, 26.84 \%, 7.68 \%, 16.33 \%, 22.48 \%$. Jika disimulasikan dengan modal investasi awal sebesar Rp1.000.000.000, maka hasil simulasi dijelaskan pada Tabel 4:

Tabel 4. Komponen Portofolio $P_{26}$

\begin{tabular}{ccccc}
\hline Kode Saham & Proporsi & $\begin{array}{c}\text { Nominal Investasi } \\
\text { (Rupiah) }\end{array}$ & $\begin{array}{c}\text { Harga Saham } \\
\text { (Rupiah/lembar) }\end{array}$ & $\begin{array}{c}\text { Proporsi } \\
\text { (lembar) }\end{array}$ \\
\hline ADRO & 0,2649 & 264.900 .000 & 1.540 & 172.012 \\
ANTM & 0,2684 & 268.400 .000 & 830 & 323.373 \\
BUMI & 0,0768 & 76.800 .000 & 65 & 1.181 .538 \\
ESSA & 0,1633 & 163.300 .000 & 270 & 608.814 \\
INCO & 0,2248 & 224.800 .000 & 3.570 & 62.969 \\
Jumlah & 1,0000 & 1.000 .000 .000 & & \\
\hline
\end{tabular}

Berdasarkan Tabel 4, maka investor dapat membeli 172.012 lembar saham ADRO, 323.373 lembar saham ANTM, 1.181.538 lembar saham BUMI, 608.814 lembar saham ESSA dan 62.969 lembar saham INCO dengan risiko sebesar $0.0263 \%$. Berdasarkan 26 portofolio saham yang di analisis, $P_{26}$ merupakan portofolio dengan kombinasi saham terbanyak dari portofolio lainnya, dan menghasilkan risiko yang terendah. Sehingga, semakin banyak variabel atau saham yang dipertimbangkan dalam satu portofolio, maka portofolio tersebut memberikan nilai risiko yang paling rendah atau dapat dikatakan yang paling optimal.

\section{Kesimpulan}

Berdasarkan hasil perhitungan portofolio, Diperoleh portofolio optimal dengan risiko yang paling rendah sebesar $0,0263 \%$ yaitu $P_{26}$. Anggota portofolio dari $P_{26}$ adalah ADRO, ANTM, BUMI, ESSA dan INCO. Proporsi masing-masing saham tersebut secara berurutan sebesar $26.49 \%, 26.84 \%, 7.68 \%, 16.33 \%$, $22.48 \%$. Jadi, seorang investor ingin berinvestasi dengan biaya investasi sebesar 1 milyar, maka investor dapat membeli 172.012 lembar saham ADRO (sebesar Rp264.900.000,00), 323.373 lembar saham ANTM (sebesar Rp268.400.000,00), 1.181.538 lembar saham BUMI (sebesar Rp76.800.000,00), 608.814 lembar saham ESSA (sebesar Rp163.300.000,00) dan 62.969 lembar saham INCO (sebesar Rp224.800.000,00). Berdasarkan 26 portofolio saham yang di analisis, $P_{26}$ merupakan portofolio dengan kombinasi saham terbanyak dari portofolio lainnya, dan menghasilkan risiko yang terendah. Sehingga, semakin banyak variabel atau saham yang dipertimbangkan dalam satu portofolio, maka portofolio tersebut memberikan nilai risiko yang paling rendah atau dapat dikatakan yang paling optimal. 


\section{Ucapan Terima Kasih}

Penulis dapat mengucapkan terima kasih kepada pihak yang ikut berperan serta dalam penelitian ini, yang telah memberikan bantuan finansial dan atau fasilitas kepada penulis.

\section{Referensi}

[1] K.A. Hasset. , A. Auerbach. 2003. On the Marginan Source of Investment Funds. Journal of Public Economics, 87, 205-232.

[2] H. Markowitz. 1952. Portfolio Section. The Journal of Finance, 7, 77-91.

[3] H. Markowitz. 1959. Portfolio Section: Efficient Diversification of Investments. J. Wiley and Sons, New York, 72.

[4] P. Embrechts, \& A. McNeil. 1999. Correlation and Dependence in Risk Management Properties and Pitfalls. Risk Journals, 11.

[5] R. Rockafellar, S. Uryasev. 2000. Optimization of Conditional Value-at-Risk. Journal of Risk, (2)3, 37.

[6] C. Acerbi, D. Tasche, 2002. A Natural Coherent Alternative to Value-at-Risk. Economic Notes, 31, 379-388.

[7] I. Kondor. 2007. On the Feasibility of Portofolio Optimization under Expected Shortfall. Quantitative Finance, 1, 389-396.

[8] F. Caccioli, \& I. Kondor. 2016. Portfolio Optimization under Expected Shortfall: Contour Maps of Estimation Error. SRC Discussion Paper, 49, 14.

[9] Sharpe, F. William.1964, Capital asset prices: A theory of market equilibrium under conditions of risk, Journal of Finance 19(3), 425-442.

[10] Lintner, John, 1965, The valuation of risk assets and the selection of risky investments in stock portfolios and capital budgets, The Review of Economics and Statistics, 47(1), 13-37.

[11] Black, Fischer, Michael Jensen, and Myron Scholes, 1972, The capital asset pricing model: Some empirical tests, in Jensen (ed.), Studies in the Theory of Capital Markets, 2-5.

[12] Tandelilin, E. 2010. Analisis Investasi dan Managemen Portofolio. Yogyakarta: Kanisius.

[13] Pflug, G.C. 2000. Some remarks on the value-at-risk and the conditional value-at-risk. In S. Uryasev, editor. Probabilistic Constrained Optimization, 272-281. Springer, Berlin.

[14] F. Caccioli, I. Kondor, Marsili, and S. Still. 2014. Lp regularized portfolio optimization. Available at SSRN 2425326; 1404.4040.

[15] C. Acerbi, D. Tasche. 2002. On the coherence of expected shortfall. Journal of Banking and Finance, 26(7):1487 - 1503. 